\title{
LA LEGISLACIÓN ECUATORIANA Y SUU ROL EN LA PREVENCIÓN, DETECCIÓN Y ERRADICACIÓN DEL LAVADO DE ACTIVOS
}

ECUADORIAN LAW AND ITS ROLE IN THE PREVENTION, DETECTION AND ELIMINATION OF MONEY LAUNDERING

\section{IRENE VALENCIA BALLADARES}

Universidad Católica de Santiago de Guayaquil

irene.valencia@cu.ucsg.edu.ec

RESUMEN

La terminología lavado de activos ha sido utilizada durante muchas décadas por entidades públicas, como la Policía Nacional, Ministerio del Interior y demás organismos involucrados en su lucha, cuyo propósito es erradicar este mal que aqueja a la sociedad ecuatoriana y que tuvo mayor repunte en la última década. Actualmente, Ecuador es considerado como un país de tránsito de drogas y todo tipo de sustancias psicotrópicas, razón por la cual han suscitado diversos casos de lavados de activos, motivo que justifica el rol de organismos competentes que conforman el CONCLA, a fin de detectar, prevenir y erradicar el desarrollo de esta práctica en territorio nacional. Bajo este contexto el presente artículo, sirve como un punto de partida para entender qué es el lavado de activos, cómo se manifiesta, quiénes lo regulan y qué sanciones se plantean para sus involucrados, con el objetivo de ir frenando de a poco esta práctica delictiva y asegurar el bienestar de los ciudadanos.

PALABRAS CLAVE: lavado de activos, delitos, sanciones, órganos reguladores.
ABSTRACT The washing active terminology has been used for decades by public entities such as the National Police, Ministry of Interior and other agencies involved in the struggle, which aims to eradicate this evil that afflicts Ecuadorian society and had greater rebound in last decade. Currently, Ecuador is considered a transit country for drugs and all kinds of psychotropic substances, why have raised several cases of washes assets, ground justifying the role of relevant agencies that make up the CONCLA, to detect, prevent and eradicate the development of this practice in the country. In this context, this article serves as a starting point to understand what money laundering, how it manifests, who regulate and what penalties are raised to its stakeholders, with the aim of going braking slowly this criminal practice and ensure the welfare of citizens

KEYWORDS: money laundering, offenses, penalties, regulatory bodies. 
INTRODUCCIÓN

El lavado de activos es una de las prácticas delictivas que mayor polémica ha generado en las últimas décadas a nivel mundial, y en el Ecuador no es la excepción. Se conoce como lavado de activos a todas aquellas acciones que utilizan los grupos delictivos organizados, para limpiar, ocultar o disfrazar el dinero que procede de actos ilícitos, con el propósito de ingresarlos dentro del sistema económico a través de la compra de bienes, creación de "empresas fantasmas”, testaferros y demás mecanismos que sean capaces de despistar a los organismos reguladores(Maldonado López, 2012).

Al hacer referencia al término "lavado de activos", es posible remitirse a los orígenes de esta práctica en la década de 1920, donde grupos criminales estadounidenses denominados "mafias", crearon una red de lavanderías que tenía como finalidad ocultar la procedencia del dinero ilícito resultante del contrabando de bebidas alcohólicas, las cuales eran prohibidas en dicha época, como parte de este antecede se adoptó la expresión "lavado de activos" o "lavado de dinero" para referirse al encubrimiento del dinero ilícito (Tondini, 2006).

Hoy en día, esta práctica normalmente suele ser relacionada inmediatamente con el dinero que procede del narcotráfico; pero acorde con la Unidad de Análisis Financiero (UAF),esto sólo constituye uno de los principales delitos, ya que dentro de esta práctica (lavado de activos) también se involucran delitos como: el tráfico de armas, la trata de blancas, las redes de prostitución, la malversación de fondos públicos,el coyoterismo, las coimas, el fraude, el terrorismo, el sicariato y todo aquello que sea considerado como "ilegal"; en resumidas cuentas, todo dinero que proceda de actos ilícitos (UAF, 2014).

Es por esta razón que todas las naciones, incluido el Ecuador, plantean dentro de sus legislaciones, una sanción bastante drástica a todas aquellas personas que formen parte de estos actos que por ser delictivos perjudican al Estado y a la sociedad en general(Asamblea Nacional Constituyente, 2008).

Es así como en Ecuador existe la "Ley de Prevención, Detección y Erradicación del Delito de Lavado de Activos y del Financiamiento de Delitos" publicada el 18 de octubre de 2005, según Registro Oficial 127 y que tuvo su última modificación el 30 de diciembre de 2010. En el mismo sentido, a esta ley se suma el actual Código Integral Penal (COIP) publicado el 10 de febrero de 2014 según Registro Oficial 180; ambas legislaciones establecen las sanciones que se aplican para los casos vinculados con el lavado de activos y financiamientos de delitos, las cuales serán analizadas posteriormente para identificar el rol que cumplen y quiénes son los organismos reguladores.

De esta manera, el presente artículo tiene como objetivo principal dar a conocer a la ciudadanía, sobre la problemática que trae consigo el lavado de activos, la forma en qué se manifiesta, los organismos que regulan esta actividad, las normativas que están enfocadas a contrarrestarlo y ciertos casos que han sido publicados por la prensa, para prevenir a los ecuatorianos sobre los riesgos que incurren al verse vinculados directa e indirectamente de esta práctica, y las consecuencias que pueden acarrear; puesto que así se contribuye a la prevención y control de estos actos delictivos y se promueve una sociedad más solidaria, justa y responsable.

\section{LA PROBLEMÁTICA DEL LAVADO DE ACTIVOS}

Como se mencionó anteriormente, el lavado de activos consiste en una práctica que tiene como finalidad ocultar la procedencia de dinero mal habido para ingresarlo en la economía de un país, mediante mecanismos que desvíen la atención de las entidades que lo regulan como: La Policía Nacional, Servicio de Rentas Internas, Superintendencia de Compañías, Superintendencia de Compañías, Ministerio de Justicia, entre otros. Para este efecto, los organismos reguladores han podido identificar tres etapas principales que se desarrollan durante el proceso de lavado de dinero:

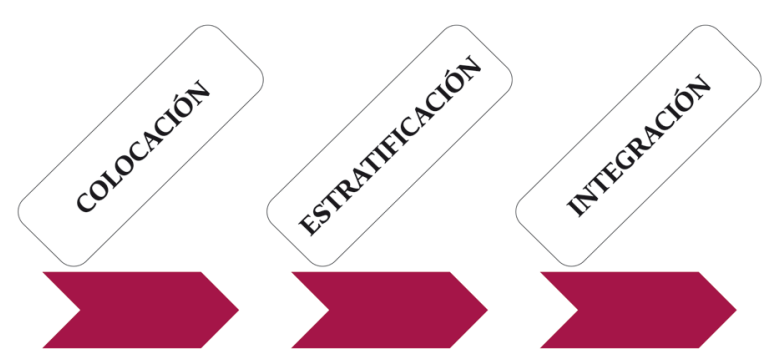

Figura1. Fases del lavado de activos.

La fase de colocación se manifiesta cuando se introducen las ganancias ilegales en el sistema financiero. Para esto, se emplean depósitos bancarios o se invierte en instrumentos financieros, para hacerlos pasar por dinero lícito. Posteriormente, la estratificación consiste en el uso del dinero para la compra de bienes o 
servicios, creación de empresa, cuentas bancarias en paraísos fiscales y demás mecanismos que los alejen de su origen delictivo, de esta forma intentan dificultar el rastreo por parte de los órganos reguladores. Finalmente, la integración consiste en el reingreso del dinero en la economía para que pueda ser utilizado normalmente por su propietario o terceros, en la compra de bienes para su uso personal, como viviendas, vehículos, alimentos, entre otros (Sánchez Brot, 2001).

Es en esta última etapa, donde precisamente suele detectarse la posible vinculación de una persona con el tema de lavado de activos, especialmente porque en muchos casos su forma de actuar llama la atención, a través de la adquisición de bienes o servicios lujosos, los cuales levantan sospechas de la procedencia del dinero, principalmente, cuando se dan cambios muy radicales que no coinciden con el perfil de ingreso o estilo de vida del sujeto en cuestión. Por ejemplo, se puede presumir que una persona está vinculada con este delito, cuando su vida empieza a tener cambios radicales y prácticamente de la noche a la mañana es capaz de comprar vehículos lujosos, viviendas, ropa, realizar viajes, y adquirir demás productos suntuarios que, antes difícilmente podía comprar.

En el mismo sentido, los supuestos líderes de estas bandas delictivas suelen utilizar testaferros o "prestanombres", que son personas que figuran propietarios de sus bienes; por ejemplo, esto se manifiesta cuando una persona que tiene un ingreso mensual de $\$ 354.00$, posee bienes a su nombre por cantidades que están por encima de su perfil de ingresos; lo cual comienza a generar dudas sobre la procedencia de su dinero y se lo considera como potencial víctima del lavado de activos.

Es por ello que los organismos reguladores, han detectado a dos sectores como los de mayor riesgo para la vinculación de lavado de activos: el sector inmobiliario y las concesionarias de vehículos, ya que estas empresas se convierten en las preferidas por estas organizaciones delictivas para desviar la atención del origen del dinero, a través de la compra de casas o autos lujosos (Uribe, 2003).

No obstante, entidades como la UAF exigen a estos sectores el cumplimiento de los artículos 2, 3, 4 y 5 de la Ley de Prevención, Detección y Erradicación del Delito de Lavado de Activos y del Financiamiento de Delitos, que consiste en la generación de reportes que justifiquen la licitud de los fondos de sus clientes, y así evitar posibles vinculaciones, ya que la omisión o desconocimiento de estas normativas no los excluye de las sanciones, que en el peor de los casos se convierten en penas de hasta 13 años de reclusión mayor.

\section{LOS CASOS MÁS RECIENTES SOBRE LAVADO DE ACTIVOS EN} EL ECUADOR

En octubre 2013, la Fiscalía a través de otros órganos reguladores pudo identificar un nuevo método que utilizaban ciertas empresas a través del Sistema Único de Compensación Regional y Económica (SUCRE), por actividad de comercio exterior entre empresas ecuatorianas y venezolanas. El resultado de esta investigación determinó la movilización de 300 operaciones en el sistema que bordearon los \$ 100 millones de dólares y como saldo dejaron cinco personas privadas de su libertad y 17 prófugos por el cometimiento de este delito (El Telégrafo, 2013).

En febrero 2014, Diario El Universo publicaba la vinculación de un ex dirigente deportivo y un ex representante legal de una empresa de seguros, en la práctica del delito de lavado de activos; información remitida por la Fiscalía General del Estado, una vez que los organismos reguladores realizaron investigaciones en donde las operaciones inusuales e injustificadas no concordaban con su perfil económico, pues se habían desviado cerca de \$ 10 millones a una cuenta de un banco en Miami (Diario El Universo, 2014).

Por otra parte, recientemente en febrero 2015, el Fiscal General del Estado, Galo Chiriboga, confirmó la creación de una nueva unidad anti lavado de activos, la misma que contará con la colaboración de los bancos del Pacífico y Pichincha, quienes de forma coordinada trabajarían con la UAF en la detección, prevención y erradicación de lavados de activos. En una rueda de prensa, el Fiscal Chiriboga manifestó que el objetivo de esta unidad es mejorar los resultados sobre el tema en cuestión, puesto que apenas el $11 \%$ de las denuncias receptadas han terminado en sentencia, es decir sólo 15 de 132 casos (Ecuavisa, 2015).

\section{LOS ORGANISMOS DE CONTROL Y LUCHA CONTRA EL DELITO DE LAVADO DE ACTIVOS}

Con la aprobación de Ley contra lavado de activos publicada en 2005, se abrió paso a la creación del Consejo Nacional Contra el Lavado de Activos (CONCLA), el cual está conformado por las siguientes entidades: 
1. La Procuraduría General del Estado.

2. La Fiscalía General del Estado.

3. La Superintendencia de Bancos y Seguros.

4. La Superintendencia de Compañías.

5. El Servicio de Rentas Internas.

6. El Servicio Nacional de Aduana del Ecuador.

7. El Ministro del Interior.

8. La Unidad de Análisis Financiero.

\section{CONSEJO NACIONAL CONTRA EL} LAVADO DE ACTIVOS ARTICULO 7

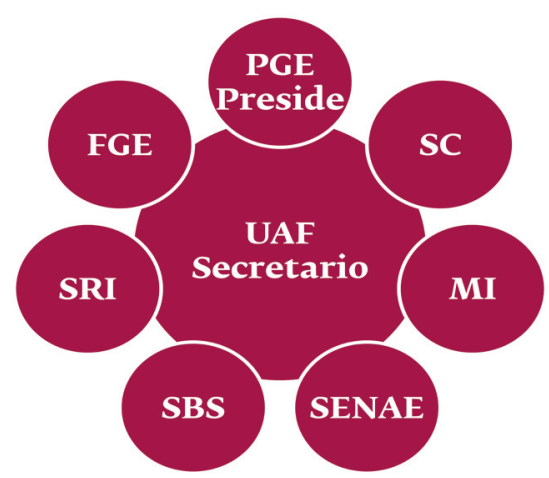

Figura 2. Entidades que conforman el CONCLA

Fuente: Superintendencia de Compañías

Estas entidades tienen como principal objetivo hacer cumplir la Ley de Prevención, Detección y Erradicación del Delito de Lavado de Activos y del Financiamiento de Delitos, a través de la realización de investigaciones a presuntos vinculados con este tipo de delitos. Las sanciones que se estipulan en los artículos 15, 16, 17 y 18 de esta Ley son:

- Prisión de 1 a 5 años, cuando el lavado no exceda los \$50,000.00

- Reclusión menor ordinaria de 3 a 6 años, cuando se encuentre montos lavados entre $\$ 50,000.00$ y $\$ 300,000.00$.

- Reclusión menor ordinaria de 6 a 9 años, para aquellas transacciones ilícitas mayores a $\$ 300,000.00$.

- Prisión de 1 a 13 años a quienes de forma dolosa realicen acciones tendientes a incriminar a una o más personas en el delito de lavados activos (Asamblea Nacional, 2010).

A esta Ley se suman las recomendaciones que dan organismos internacionales como el Grupo de Acción Financiera Internacional (GAFI), cuyo fin es la elaboración de medidas que combatan todas las prácticas relacionadas con el lavado de activos bajo todas sus modalidades. Este organismo intergubernamental está integrado por 26 países y en conjunto han planteado un manual conocido como las 40 Recomendaciones de la GAFI, con la finalidad de luchar contra el financiamiento de delitos, principios que contemplan responsabilidades del entorno jurídico penal y policial, sistema financiero y la cooperación internacional.

De esta forma, estas entidades lo que buscan es salvaguardar la integridad de las personas naturales o jurídicas que puedan verse involucradas culposa o dolosamente, en asuntos de lavado de delitos, con la finalidad de frenar esta práctica.

DISCUSIÓN

A lo largo de este artículo se ha hecho una explicación de la definición del término lavado de activos, de su forma de operar, de los organismos reguladores y las sanciones que se plantean para las personas que de una u otra forma podrían verse inmersas en este delito; y los casos más recientes en el Ecuador en los últimos dos años. Todo esto para marcar un precedente del impacto nocivo que genera este mal, considerado como uno de los principales delitos en todo el mundo. Sin embargo, autores como Rodríguez (2004) consideran que hay ciertas diferencias en los términos lavado de activos, lavado de dinero y blanqueo de capitales, basándose en las siguientes características:

LAVADO DE ACTIVOS

Mecanismos y conductas que se aplican en organizaciones delictivas para legalizar el dinero que proviene del narcotráfico.

LAVADO DE DINERO

Propósito idéntico al lavado de activos, pero el dinero proviene de todo tipo de delitos

\section{BLANQUEO DE CAPITALES}

Acciones que se utilizan para utilizar bienes que proceden de actos delictivos

Figura 3. Diferenciación de las acepciones relacionadas al lavado de activos

Si se observa detenidamente cada definición, el contenido es prácticamente el mismo, salvo el primer término en el cual está ligado exclusivamente con el narcotráfico, pero en sí 
las tres plantean mecanismos, acciones o todo tipo de mañas que empleen las organizaciones delictivas para limpiar el dinero mal habido y así utilizarlo normalmente, sin dejar rastros de su origen.

Es por esta razón, que es importante hacer conciencia en el papel que juegan los organismos reguladores pertenecientes al CONCLA, enfocados en combatir este mal que aqueja a todas las sociedades a nivel mundial. Lastimosamente, hay naciones como Colombia y México donde prácticamente este problema forma parte del diario vivir, a tal punto que el término lavado de activos o narcotráfico se lo relacionada inmediatamente con los carteles que operan en estos países (Bareño - Dueñas, 2009). A esto se alegan los diversos mecanismos que se han diseñado para prevenir a la sociedad, basados en las legislaciones que lo sancionan.

La discusión de este problema radica en los involucrados en este problema, puesto que $\mathrm{mu}^{-}$ chas personas suelen ser vinculadas sin poseer una participación directa, y lamentablemente, la Ley no exime de responsabilidad a estas personas, sino que los añade a la lista de presuntos implicados en el delito (Gaviria Uribe \& Mejía Londoño, s.f.). Por ello, depende de la función judicial establecer hasta qué punto una persona es o no responsable de formar parte de una red de lavado de activos, ya que algunos suelen "pecar de incautos" al momento de requerir una oportunidad de trabajo o negocio, que les ayude a mejorar su calidad de vida. De esta forma, la situación se agrava más porque se juega con el anhelo de las personas de escasos recursos en ser las víctimas de este tipo de actos delictivos.

Bajo este contexto, es importante plantear artículos que promuevan en la ciudadanía el conocimiento sobre el problema objeto de estudio, a fin de detectar posibles indicios de lavado de activos y sean denunciados a los órganos para frenar este delito, y así liberar a la sociedad de un mal que corrompe y va en contra del Buen Vivir (SENPLADES, 2013).

CONCLUSIONES

Como conclusiones a este trabajo se pueden establecer las siguientes:

1. El lavado de activos es una práctica que aqueja a todas las sociedades del mundo, porque consiste en el encubrimiento del dinero que procede de todo tipo de actos delictivos, principalmente del narcotráfico.
2. Los organismos reguladores han identificado tres procesos acerca del modo de operación de este delito: colocación, estratificación e integración. Por ello, establecen ciertas recomendaciones y exigen procedimientos a las empresas que más riesgo representan de verse involucradas en este problema, con la finalidad de combatirlo.

3. Las sanciones para este delito se encuentran establecidas en el Código Orgánico Integral Penal y en la Ley de Prevención, Detección y Erradicación del Delito de Lavado de Activos y del Financiamiento de Delitos, con penas de hasta 13 años de prisión.

\section{RECOMENDACIONES}

- Es importante que la ciudadanía tome conciencia de esta problemática para prevenir un posible vínculo con organizaciones delictivas y así contribuyan, por medio de denuncias, en la erradicación de esta práctica, todo esto con el propósito de promover una sociedad justa, solidaria y responsable.

- Es de interés del Estado ecuatoriano, desarrollar políticas estatales con visión y misión en crear nuevas medidas de control para esta actividad delictiva.

REFERENCIAS BIBLIOGRÁFICAS

Asamblea Nacional (2010): Ley de prevención, detección y erradicación del delito de lavado de activos y financiamiento de delitos. Quito, Ecuador: Registro Oficial 352.

Asamblea Nacional Constituyente (2008): Constitución Política de la República del Ecuador. Quito, Ecuador.

Bareño - Dueñas, S. M. (2009): Mecanismos de contabilidad para prevenir y detectar el lavado de activos en Colombia. Bogotá, Colombia: Pontificia Universidad Javeriana - Universidad Externado de Colombia.

Diario El Universo. (19 de febrero de 2014): 5 presos por un presunto caso de lavado de activos. Obtenido de http://www.eluniverso.com/ noticias/2014/02/19/nota/2205136/5-presospresunto-caso-lavado-activos.

Ecuavisa. (13 de febrero de 2015): Fiscalía fortalece lucha contra el lavado de activos con unidad especializada. Obtenido de http:// www.ecuavisa.com/articulo/noticias/ nacional/99242-fiscalia-fortalece-lucha-contra-lavado-activos-unidad-especializada. 
El Telégrafo. (11 de octubre de 2013): Fiscalía desbarata nuevo método de lavado de dinero. Obtenido de http://www.telegrafo.com.ec/ noticias/informacion-general/item/fiscaliadesbarata-nuevo-metodo-de-lavado-de-dinero.html

Gaviria Uribe, A., \& Mejía Londoño, D. (s.f.): Políticas antidroga en Colombia: éxitos, fracasos y extravíos. Bogotá, Colombia: Universidad Los Andes.

Maldonado López, S. (2012): Lavado de Activos. Cuenca, Ecuador: Facultad de Derecho Penal Universidad del Azuay.

Rodríguez Cárdenas, J. P. (18 de agosto de 2004): El lavado de activos culpso o imprudente y su implicaciones en el sector financiero. Obtenido de http://heinonline.org/HOL/ LandingPage?handle=hein.journals/ contxto18\&div $=9 \&$ id $=\&$ page $=$
Sánchez Brot, L. (2001): Lavado de dinero - delito transnacional. Buenos Aires, Argentina: Universidad de Buenos Aires.

SENPLADES. (2013): Plan Nacional para el Buen Vivir 2013-2017. Versión Resumida. Quito, Ecuador: Secretaría Nacional de Desarrollo .

Tondini, B. (2006): Blanqueo de capitales y lavado de dinero: su concepto, historia y aspectos operativos. Centro Argentino de Estudios Internacionales, 38.

UAF. (2014): ¿Qué es el lavado de activos? Obtenido de http://www.uaf.cl/lavado/

Uribe, R. (2003): Cambio de paradigmas sobre el lavado de activos. Unidad Antilavado de Activos, CICAD/OEA. 